Journal of Applied Finance \& Banking, Vol. 11, No. 4, 2021, 79-99

ISSN: 1792-6580 (print version), 1792-6599(online)

https://doi.org/10.47260/jafb/1144

Scientific Press International Limited

\title{
Measuring Market Risk of Commercial Banks Implementing VaR with Historical Simulation Approach
}

\author{
Minhaz-Ul-Haq ${ }^{1}$
}

\begin{abstract}
This paper attempts to picture the impact of the market risk of ten commercial banks located in Bangladesh with the help of a non-parametric model known as the Historical Simulation Approach over the course of eight years. These banks' daily stock prices were used as inputs and analyzed in Microsoft Excel by means of Percentile and LN function. The study revealed market risk exposure as third, second-and first-generation banks from the least to the highest. It also pointed out the ups and downs of these banks' share prices in the selected period. Further analysis showed the portfolio $\mathrm{VaR}$ estimation for different time intervals.
\end{abstract}

JEL classification numbers: G32.

Keywords: Value-at-risk, Historical Simulation, Market Risk, Confidence Interval.

${ }^{1}$ Department of Banking and Insurance, University of Dhaka.

Article Info: Received: April 13, 2021. Revised: April 30, 2021.

Published online: May 12, 2021. 


\section{Introduction}

Although commercial banks are one of the agents of economic growth, they are subject to various risks. Market risk standing for the loss of investment due to a change in the market factors such as currency, interest rate, commodity, equity, inflation etc. is often called 'systematic risk' because the factors responsible for such risk can impact the entire market condition. Thus, market risk needs to be addressed, quantified and measured if commercial banks want to function correctly. VaR standing for value-at-risk is an analytical approach used to portray the scenario of market risk exposure of commercial banks. It is an analytical tool that determines the maximum amount of losses investments can incur in a certain period with prespecified confidence intervals. Confidence intervals are simply the percentage bracket upon which we can forecast the maximum loss. VaR can be calculated in three ways as Historical simulation, variance-Covariance matrix and Monte Carlo simulation approach. In this study, the historical simulation method was used to calculate VaR for ten local commercial banks of Bangladesh and for the total portfolio. This study calculated VaR for 1-day and 10-day at three confidence intervals of $90 \%, 95 \%$ and $99 \%$.

The structure of this paper is as follows: Section 02 points out the objective of the study; Section 03 discusses the relevant literature; Section 04 is the methodology that talks about data type and data collection procedure; Section 05 is the core of this study, revealing the analysis along with results and Section 06 has ended the paper with some remarks.

\section{Literature Review}

Market risk arises due to the adverse movement of prices within various components of the market. For instance, interest rate movement can create market risk for financial institutions. Market risk is one of the core risks of banking institutions. Among various models for measuring market risk, the standard one is VaR (Value-at-risk) approach. Berkowitz et al. (2011) suggested that there is a large number of risk factors that can impact the results of market risk for large organizations and it is very difficult to forecast the daily returns. This study is going to evaluate the market risk of some selected commercial banks of Bangladesh with the help of the historical simulation approach and at the same time with the implementation of the Value-at-risk model. In this section, previous research ideas and models will be discussed which are relevant to this study.

Uylangco and Li (2016) suggested that VaR models with shorter time frame give better results than more extended periods. This study was conducted on Australian banks to establish that methods and parameters selection has played a crucial role in capital adequacy during the Global Financial Crisis. Basel II faced huge criticism during that period because it failed to minimize the downside risk. But this study found that the revised methodology for using VaR under Basel III was appropriate. Value-at-Risk ( $\mathrm{VaR})$ refers to a risk measurement strategy that shows the worst loss in a given time frame and the amount of that loss will not be exceeded at that 
particular confidence interval as per the suggestion of Jorion (2007) and Alexander (2008). Allen and Powell (2007) tried to demonstrate market risk at the industry level with the help of VaR measures. The authors used the Conditional Credit VaR methodology, and it allowed banks to address industry risk. The historical simulation method uses previous calculations to predict the future scenario. One advantage of this method is that it does not make any assumption for changing risk factors. It is a more reliable method, although it has some hidden risk factor addressed by Winker and Maringer (2007).

Grum (2007) found different results while measuring market risk with different approaches. This study pointed out two methods for calculating VaR. One method was simply the historical simulation, and the other one was volatility and timeweighted historical VaR. The study claimed that the second method gave a smaller VaR calculation than the first one. This paper argued that the historical simulation method does not consider returns to be weighed against time. He suggested that returns should be measured on a time-weighted approach. In this study, data from some commercial banks of Slovenia were used. These banks had two ways to calculate capital charges for their specific market risk exposure. The Bank of Slovenia, which is the central bank of Slovenia, gave commercial banks to choose from the above two methods, such as a standard method or an internal method. This paper used volatility and time-weighted historical simulation as an internal model to calculate the market risk faced by these banks. The historical simulation is a popular method due to its independence of the spread of risk factors. In calculating security risk, commercial banks may find anomaly between the results of the historical approach and return portfolio. Despite the disadvantage, $73 \%$ of the banks in the world use the historical simulation for calculating VaR (Smit, 2009).

Smit (2009) found that historical simulation VaR contains little insight into forecasting future volatility. This study included some US and international commercial banks to measure the accuracy of the VaR method. VaR is known as a standard measure of market risk (Jorion, 2007). This paper primarily focused on the $\mathrm{VaR}$ disclosure and tried to measure VaR accuracy. The authors tried to calculate the VaR-Disclosure-Index of the ten largest US banks. Their study period was from 1996 to 2005. The study showed that the level of VaR disclosure depends on regional areas of commercial banks. Some countries impose greater disclosure where other countries require no disclosure at all, i.e., China. The authors later extended their study into Canada and found that the US banks have less disclosure level than Canadian banks. They also argued that VaR has little impact on predicting future volatility. In a similar study, Jorion (2007) concluded that four out of eight US commercial banks displayed statistically sound and significant results in future forecasting. Although these studies seem similar in nature, the sample size is significantly different for each study.

Bangladesh is one of the emerging economies of the world. It has a wide variety of banks serving numerous purposes for its population. A study involving commercial banks of Bangladesh, done by Alam and Musukujjaman (2011) tried to portray the scenario of overall risk management practices of commercial banks in Bangladesh. 
This study was based on a descriptive manner with a five-point Likert scale being the analytical tool for five commercial banks. The paper tried to focus on the risk management culture in Bangladeshi banks. The study concludes that there are two primary ways of managing risk by these banks such as 'internal rating system' and 'risk-adjusted rate of return on capital'. The emergence of ICT or information and communicative technology has made the path of banking very easy, especially for online-based banking activities. Although the development of ICT has enabled banks to reach in such places that were previously unreachable, this gives rise to more competition and a newer set of risk Yap et al. (2011). To address such risks, Basel I, II and III was implemented in many countries and Bangladesh is no exception to that list. The authors here tried to cover commercial banks' risk management practices in Bangladesh under the BASEL accord.

No previous study was conducted with these banks in our country before. A study was done addressing the Risk Management Practices with some selected commercial banks in Bangladesh by MD. ZAHANGIR ALAM and MD. MASUKUJJAMAN.

But that study was solely concentrated on the risk management practices and they did not use any of the VaR techniques. There is no other previous study that measured market risk on considering the banks in Bangladesh. Most of the previous studies tried to focus on the accuracy of the VaR model rather than calculating and comparing VaR estimations of various banks and portfolio. Some other studies focused on the criticisms of this method as it did not play out as expected during the global financial crisis.

The study focused on the non-parametric model of calculating VaR whereas other studies used parametric models to estimate VaR. Thus, the literature gap is clearly visible. The sole purpose of this study does not match with any of the previous research. In this study, historical simulation is used as it is the simplest nonparametric method for calculating VaR. In recent times, COVID-19 has been the greatest threat to any economy. Banks should be able to prepare themselves for such hazardous situation. History suggested that critical situation can impact the economy in numerous ways. One of the mentionable criticisms of $\mathrm{VaR}$ is that its estimation was not sufficient enough to absorb the shocks during Global Financial Crisis. Market risk can be a challenging competitor in such difficult times. Thus, the prospect and importance of measuring market risk should have an urgent need for further studies.

\section{Objective}

The objective of this study is to measure the market risk of ten commercial banks and to calculate their market risk exposure with the help of the VaR (value-at-risk) model using the Historical Simulation method. 


\section{Methodology}

\subsection{Research Design and Data Collection Procedure}

This study is an empirical research with a quantitative model. It used secondary data. The closing stock prices of ten local commercial banks are collected from the Dhaka Stock Exchange website. For the literature review section, it followed Market Risk and $\mathrm{VaR}$ techniques related articles.

\subsection{Data Analysis Technique}

One of the main aspects of this study is to determine the return distribution. For that purpose, the average percentage return was calculated from the historical stock prices to generate VaR estimates. The study also used trend analysis of the ten bank's stock value for the period of nine years. The study also calculated the average daily return in BDT. Average daily percentage returns were used to calculate daily gains and losses for each of the banks. With the help of those returns, VaR is calculated for each of the banks and for the overall portfolio as well.

The formula for calculating bank VaR using the historical simulation method has several steps. The first step is known as 'calculating daily returns' where daily price changes are calculated by dividing today's stock price with yesterday's stock price and taking the $\ln$ function. The second step is 'applying the price change to the current portfolio'. Here each bank's hypothetical invested amount is multiplied by the daily return to determine daily price change. The third and final step is 'determining bank VaR and portfolio VaR'. In this step, previously calculated daily profit or loss is used to generate VaR estimates for each of the banks and the portfolio. The daily price change is selected and the percentile function of Microsoft Excel is used. Finally, VaR estimates are calculated in this manner.

After data has been organized in the proper format, data are analyzed to derive the results of this study. The primary tool for analyzing the organized data in this study is Microsoft Excel version 2019. All the daily stock prices were listed in one excel sheet. Later, average daily returns were calculated using Microsoft Excel Formula. $\mathrm{VaR}$ was calculated with the excel percentile function.

\section{Empirical Analysis with Discussion}

Although Portfolio Theory and VaR model share some similarity between them, the $\mathrm{VaR}$ approach interprets the risk as to the likelihood of maximum loss. Historical $\mathrm{VaR}$ assumes that the future performance of our investment will follow the same pattern as of the past. In this study, ten local commercial banks of Bangladesh were selected and considering their daily closing share price from the period 2012 to 2020 , individual bank VaR and portfolio VaR were calculated. 


\subsection{Trend Analysis of Daily Stock Price for Ten Local Commercial Banks}

In the following, the trend of the market value of each bank's share is demonstrated through a chart. The trend of the stock prices of these banks are analyzed and discussed briefly in the following graphs:

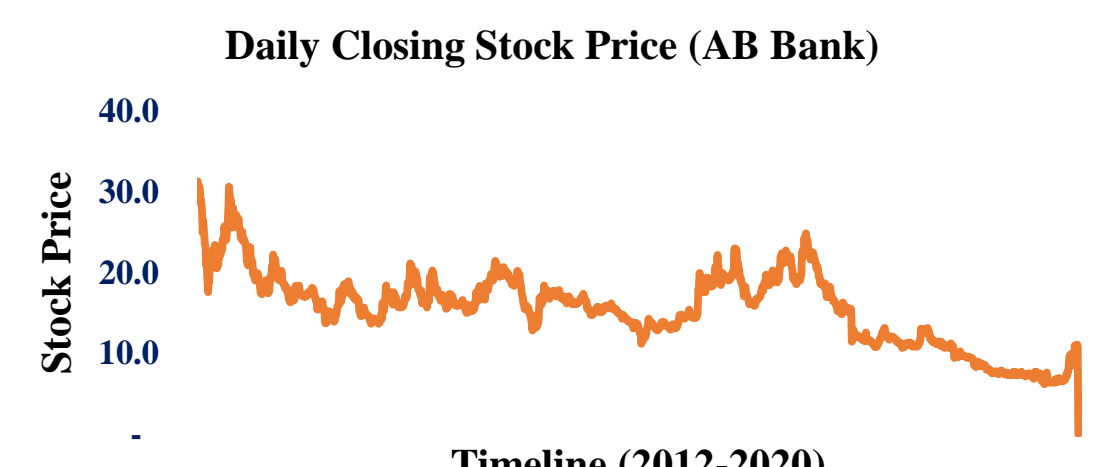

Sources of Data: DSE Database

Figure 1: Daily closing stock price of AB Bank Ltd. from 2012-2020

At the beginning of 2012, AB Bank had a share worth 31.3 BDT. Over the course of time, its price declined and ended at 10.8 BDT. Thus, $\mathrm{AB}$ bank's daily share price has declined by $66 \%$ in nine years.

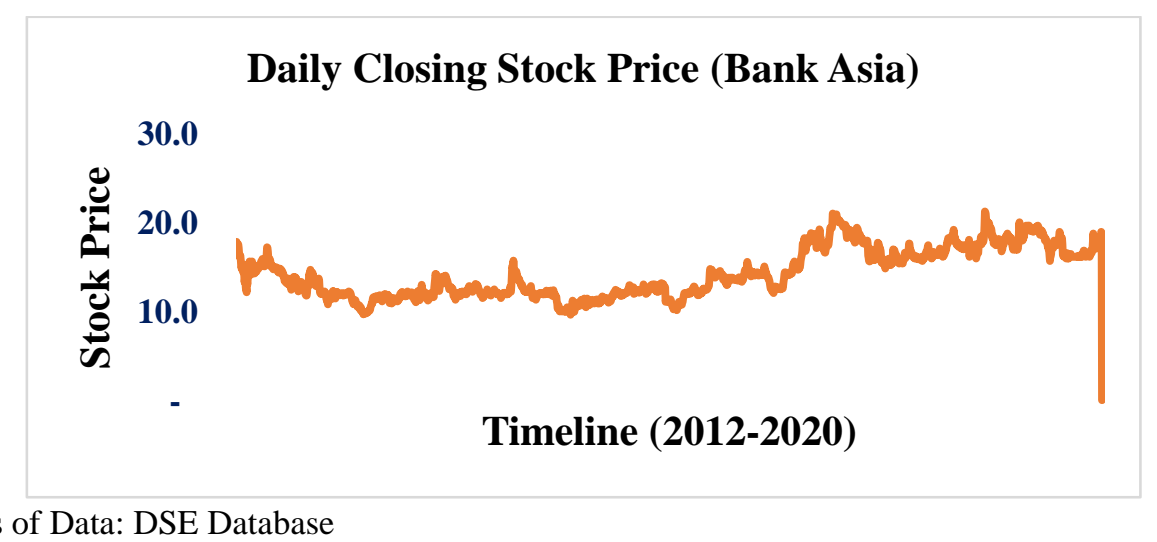

Sources of Data: DSE Database

Figure 2: Daily closing stock price of Bank Asia Ltd. from 2012-2020

Bank Asia started with a share price of 17.9 BDT in January 2012, and as of September 2020, its share price was recorded at 18.9 BDT. In the last nine years, Bank Asia's daily share price has increased by a margin of $6 \%$. 


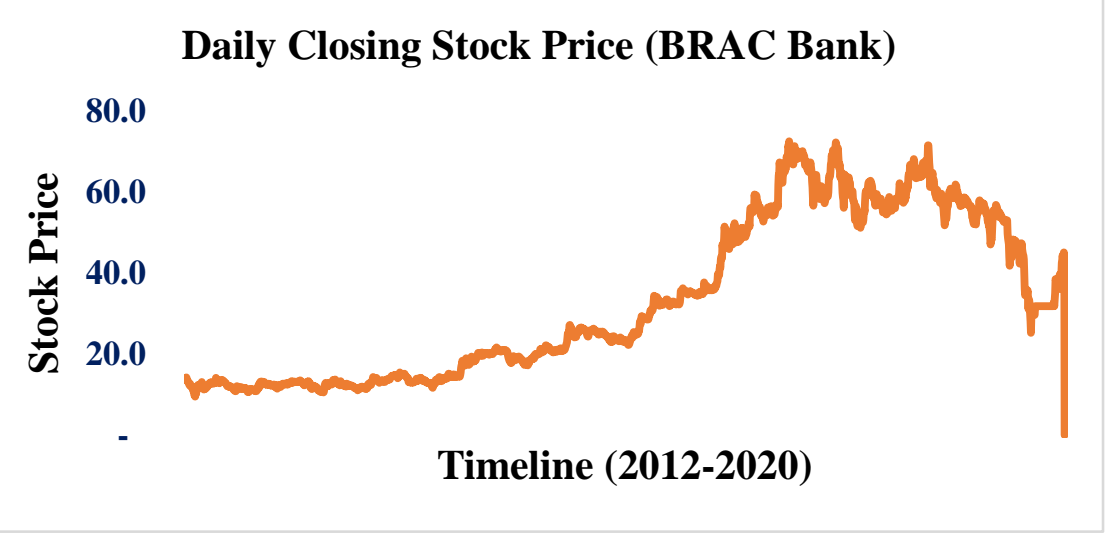

Sources of Data: DSE Database

Figure 3: Daily closing stock price of BRAC Bank Ltd. from 2012-2020

Among these ten banks, BRAC Bank's daily share price has seen a tremendous change. In January 2012, the share price of BRAC Bank was merely 13.9 BDT. Over nine years, in 2020, it has become 44.1 BDT which is a $217 \%$ increase.

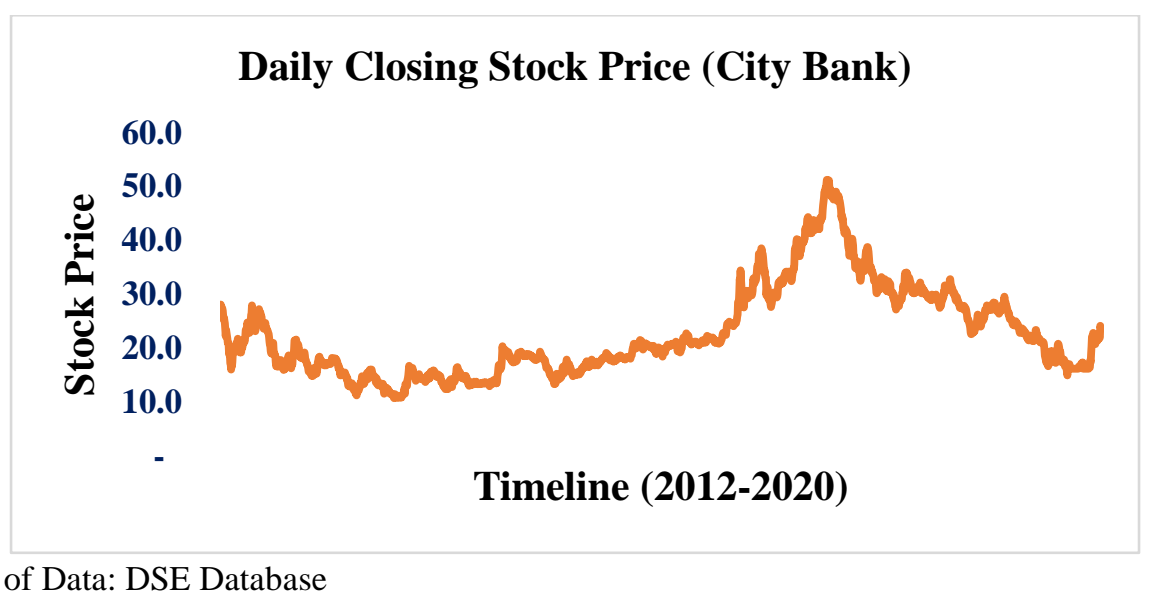

Sources of Data: DSE Database

Figure 4: Daily closing stock price of City Bank Ltd. from 2012-2020

City bank's stock price declined from 28.2 BDT to 23.9 BDT (15\% decline) in that nine-year period. 


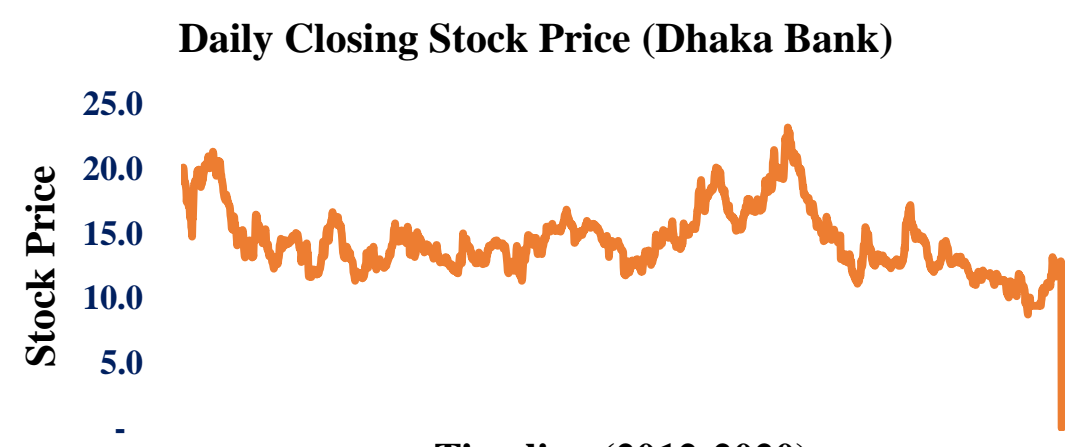

Timeline (2012-2020)

Sources of Data: DSE Database

Figure 5: Daily closing stock price of Dhaka Bank Ltd. from 2012-2020

In January 2012, it had a stock worth 19.8 BDT which has become 12.8 BDT (35\% decline) at the end of 2020.

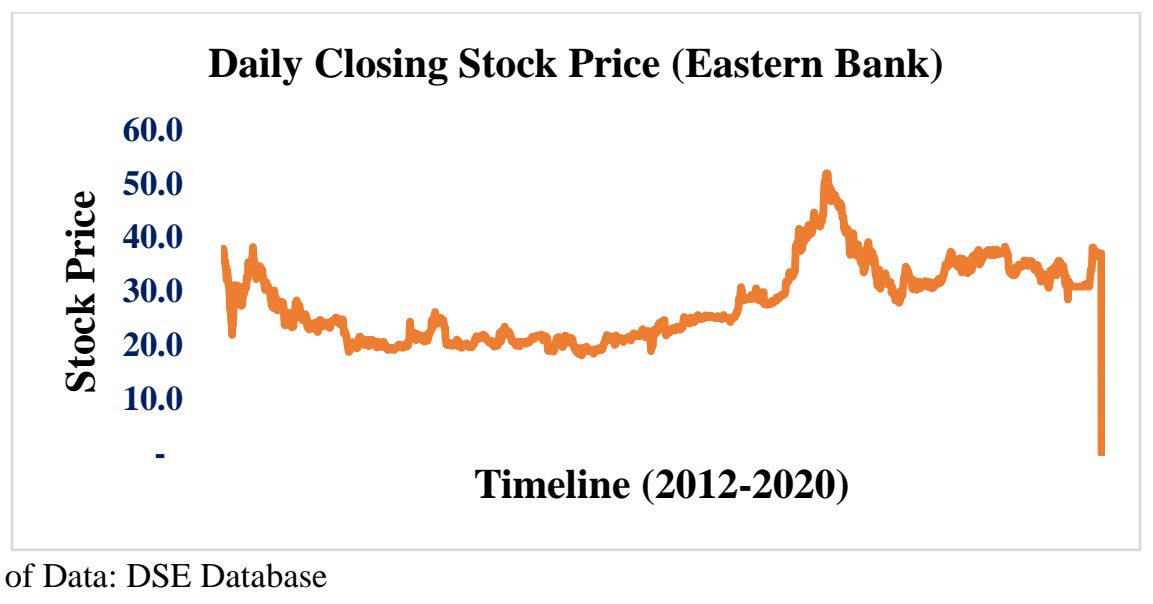

Sources of Data: DSE Database

Figure 6: Daily closing stock price of Eastern Bank Ltd. from 2012-2020

Eastern Bank's daily stock price has remained somewhat the same in the calculated period. In the beginning, its share price was recorded at 37.3 BDT and ended at 37.1 BDT or a $0.4 \%$ decline. 


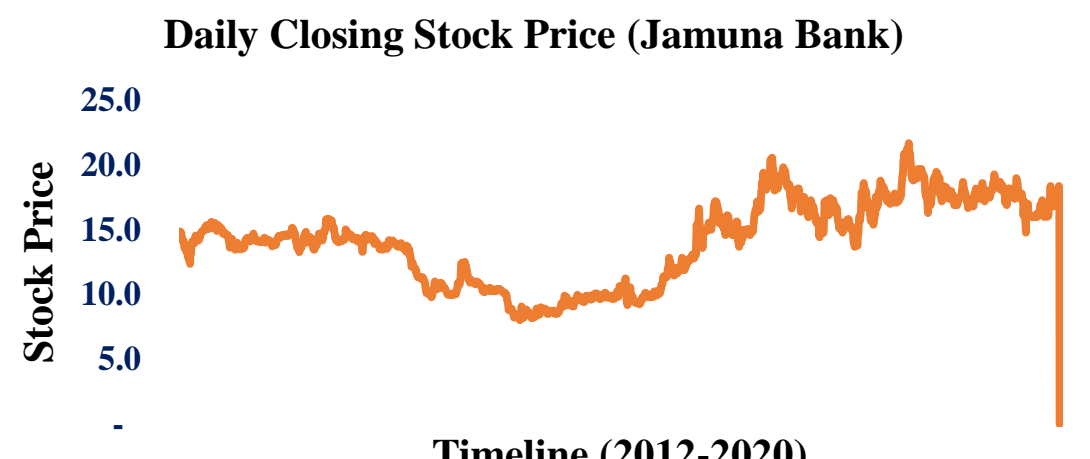

Sources of Data: DSE Database

Figure 7: Daily closing stock price of Jamuna Bank Ltd. from 2012-2020

Jamuna Bank has improved its share price from 14.9 BDT to 18.2 BDT which is a $22 \%$ increase.

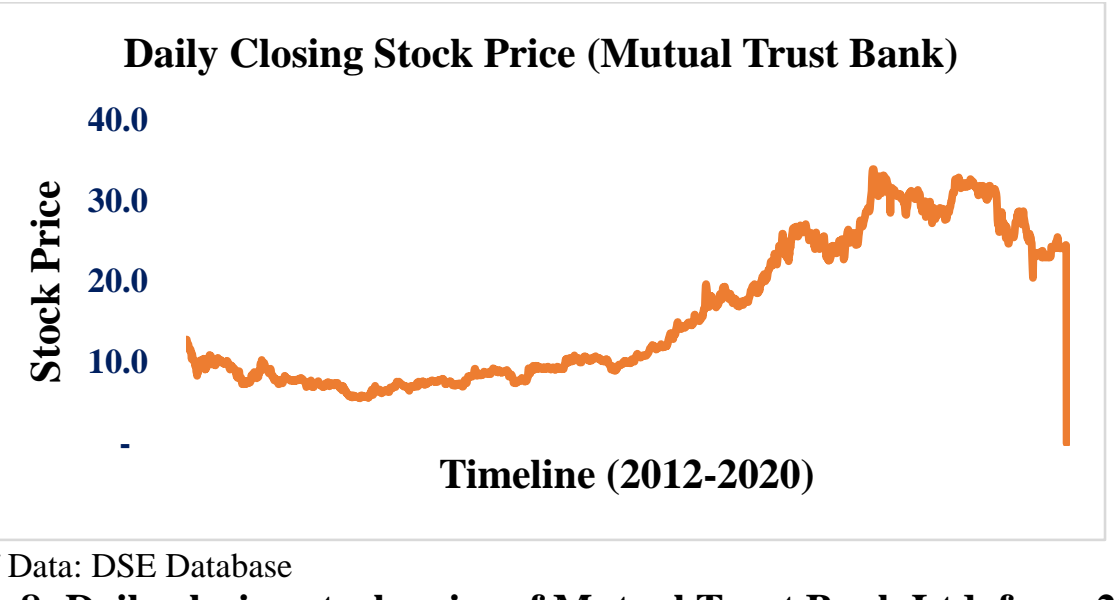

Sources of Data: DSE Database

Figure 8: Daily closing stock price of Mutual Trust Bank Ltd. from 20122020

In the nine-year period, MTB's stock value has almost doubled from 12.8 BDT to 24.4 BDT. Mutual Trust Bank has increased its stock value by $90 \%$ in that period. 


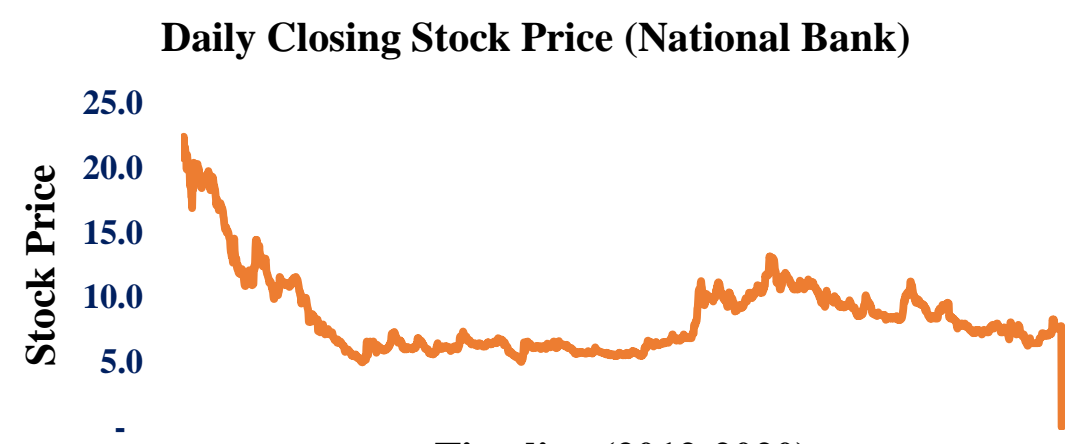

Timeline (2012-2020)

Sources of Data: DSE Database

Figure 9: Daily closing stock price of National Bank Ltd. from 2012-2020

National bank has seen a $63 \%$ decline in its stock price, from 21 BDT to $7.8 \mathrm{BDT}$.

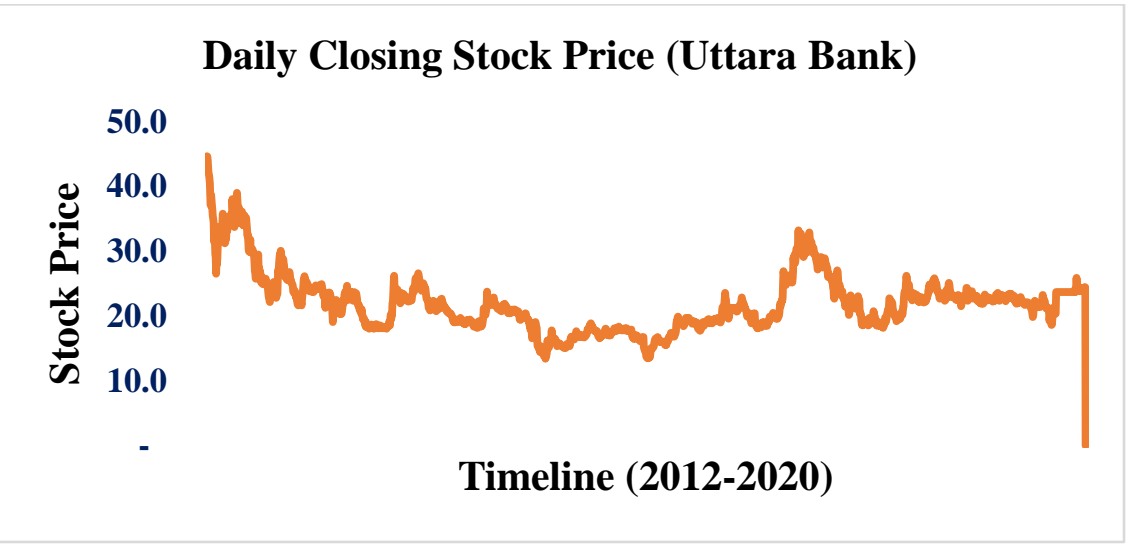

Sources of Data: DSE Database

Figure 10: Daily closing stock price of Uttara Bank Ltd. from 2012-2020

Uttara Bank has lost its stock worth by almost 50\%. From 44.6 BDT to 24.4 BDT. In percentage terms, it is equivalent to a $45 \%$ reduction.

\subsection{Trend Summary}

The above discussion covers the ups and downs of the share prices of the selected ten local commercial banks. It is evident that some of the banks performed very well in the nine-year period, whereas some did not function as per their reputation. Among all the banks, BRAC Bank has outperformed everyone with a more than $200 \%$ increase in its stock value. On the other hand, AB Bank has the highest decline percentage rate in its share price in the selected period, with a $66 \%$ reduction in its stock value. From a different perspective, second and third-generation banks are better off than first-generation banks. All the first-generation banks have shown a decline in their stock value. Third generation banks have increased their stock 
worth by $239 \%$ aggregately.

The trend in stock prices of these banks is given in the following table:

Table 1: Trend in stock prices of ten local commercial banks from 2012-2020

\begin{tabular}{|c|c|}
\hline Banks & Stock Price Movement (\%) \\
\hline AB Bank Ltd. & -66 \\
\hline Bank Asia Ltd. & +6 \\
\hline BRAC Bank Ltd. & +217 \\
\hline City Bank Ltd. & -15 \\
\hline Dhaka Bank Ltd. & -35 \\
\hline Eastern Bank Ltd. & -0.4 \\
\hline Jamuna Bank Ltd. & +22 \\
\hline Mutual Trust Bank Ltd. & +90 \\
\hline National Bank Ltd. & -63 \\
\hline Uttara Bank Ltd. & -45 \\
\hline
\end{tabular}

Sources of Data: DSE Database

\subsection{Average Daily Stock Return (\% \& BDT) of Ten Local Commercial Banks}

Daily percentage return is calculated from the daily stock prices of the selected banks. Later on, daily return (on amount) is calculated from the funds hypothetically invested in these banks. In order to calculate the percentage daily return, today's share price is divided by yesterday's share price. Then the result is converted into log-returns by simply putting ' $I n$ ' in the previously mentioned formula. For example, let $\mathrm{x}=$ today's share price of Eastern bank limited=22.4 BDT and $\mathrm{y}=\mathrm{yesterday's} \mathrm{share}$ price of Eastern bank limited=26.7. Thus, the daily percentage return of EBL's stock for today will be $=\ln (\mathrm{x} / \mathrm{y})$. In this manner, the daily percentage return is calculated for the selected banks for a period of eight years, from 2012 to 2020. After calculating the daily percentage return, daily gains or losses are calculated for these banks. For this study, the total investment portfolio was assumed to be 50 lakhs BDT. It was hypothetically considered, and the weight was given on the basis of the generations of the banks. Each daily percentage return is then multiplied by the hypothetically invested amount to calculate daily gains or losses.

The hypothetical investment distribution is depicted in the following table: 
Table 2: Distribution of Hypothetical Portfolio

\begin{tabular}{|c|c|c|c|}
\hline Generations & Banks & Weight & BDT \\
\hline 1 & $\begin{array}{c}\text { AB Bank Ltd. } \\
\text { City Bank Ltd. } \\
\text { National Bank Ltd. } \\
\text { Uttara Bank Ltd. }\end{array}$ & $60 \%$ & $7,50,000$ \\
\hline 2 & $\begin{array}{c}\text { Dhaka Bank Ltd. } \\
\text { Eastern Bank Ltd. } \\
\text { Mutual Trust Bank Ltd. } \\
\text { Bank Asia Ltd. }\end{array}$ & $30 \%$ & $3,75,000$ \\
\hline 3 & $\begin{array}{c}\text { BRAC Bank Ltd. } \\
\text { Jamuna Bank Ltd. }\end{array}$ & $10 \%$ & $2,50,000$ \\
\hline \multicolumn{3}{|c|}{ Total Portfolio = 50,00,000 BDT } \\
\hline
\end{tabular}

Sources of Data: Author's Assumption

First, second and third-generation banks were given $60 \%, 30 \%$ and $10 \%$ weight respectively. Each bank's invested amount is shown in the above table with respective weight distribution.

From the daily percentage return and daily gains and losses, average percentage return and average daily gains or losses are determined and pointed out in the following table:

Table 3: Average Return (\% and BDT) of ten local commercial banks from 2012-2020

\begin{tabular}{|c|c|c|}
\hline Banks & Average (\%) Return & Average (BDT) Return \\
\hline AB Bank Ltd. & $-0.0517 \%$ & -388 Taka \\
\hline Bank Asia Ltd. & $5.9938 \%$ & 22,477 Taka \\
\hline BRAC Bank Ltd. & $116 \%$ & 140 Taka \\
\hline City Bank Ltd. & $-0.0080 \%$ & -60 Taka \\
\hline Dhaka Bank Ltd. & $-0.0211 \%$ & -79 Taka \\
\hline Eastern Bank Ltd. & $-0.0006 \%$ & -2 Taka \\
\hline Jamuna Bank Ltd. & $0.0098 \%$ & 25 Taka \\
\hline Mutual Trust Bank Ltd. & $0.0312 \%$ & 117 Taka \\
\hline National Bank Ltd. & $-0.0482 \%$ & -361 Taka \\
\hline Uttara Bank Ltd. & $-0.0293 \%$ & -219 Taka \\
\hline
\end{tabular}

Sources of Data: Author's Calculation

While six out of the ten banks have shown a negative average return, BRAC bank has shown a $116 \%$ positive average return. This is evidence of a $216 \%$ increase in its stock price during that timeline. Bank Asia holds the second position with an almost $6 \%$ positive average return. The remaining banks have a close average return ranging from $0.00 \%-0.05 \%$. Among them, $\mathrm{AB}$ bank has a negative average return of $-0.0517 \%$. In the case of average BDT return, Bank Asia exceeds every other 
bank by a considerable margin with an average BDT return of 22,477 taka. Mutual Trust holds the second position with an average BDT return of 115 taka. In contrast, AB bank has average daily losses of BDT 388 taka. Although BRAC bank had a very unusual daily average return, the average BDT return for BRAC bank is only 140 BDT. The reason is due to the different weights given as per the generations of the banks.

\subsection{Value-at-risk of Ten Local Commercial Banks at Different Time Intervals}

VaR estimates the probable loss that might occur from an investment while considering natural market forces are in play. For example, let's assume 'A' has an investment of 10,000 BDT. With the help of VaR estimates, we can forecast that in a specific day or for a particular period the highest loss 'A' can incur for that tenthousands taka.

In this study, VaR was calculated from the daily returns in BDT of each bank. For the selected ten local commercials banks, an excel column was created with the daily returns in BDT for the nine years. Later on, each bank's VaR was calculated with the help of percentile function in excel. It is known that VaR estimates can fall within various confidence levels. Confidence intervals are used as a measure to predict the forecast with different accuracy level. For instance, we can use $90 \%$ or $95 \%$ or $99 \%$ confidence intervals. Each of them represents our accuracy in predicting the forecast. For instance, we can predict with $90 \%$ or $95 \%$ or $99 \%$ certainty that our VaR estimates will be significant or simply the calculated loss will not exceed that amount. The VaR estimates of the selected ten banks are discussed in the following tables:

Table 4: Value-at-risk of AB Bank Limited at different time intervals from 2012-2020

\begin{tabular}{|c|c|c|}
\hline \multicolumn{3}{|c|}{ Value-at-risk of AB Bank Limited } \\
\hline Time Periods & Confidence Level (\%) & Amounts in BDT \\
\hline \multirow{3}{*}{ 1-Day } & $90 \%$ & $-18,413$ \\
\cline { 2 - 3 } & $95 \%$ & $-24,740$ \\
\cline { 2 - 3 } & $99 \%$ & $-41,292$ \\
\hline \multirow{3}{*}{ 10-Day } & $90 \%$ & $-58,228$ \\
\cline { 2 - 3 } & $95 \%$ & $-78,236$ \\
\cline { 2 - 3 } & $99 \%$ & $-1,30,578$ \\
\hline
\end{tabular}

Sources of Data: Author's Calculation

Table 4 gives an idea about the VaR estimates of $\mathrm{AB}$ Bank. It is calculated on two different time periods. 1-day VaR uses a distribution of daily returns, whereas 10day $\mathrm{VaR}$ uses a distribution of returns ten-day apart. As we can see in the table that $\mathrm{VaR}$ calculations and confidence intervals are positively related. The higher the confidence level, the greater the VaR estimates. It is because we want to be more 
accurate in our prediction. Thus, VaR estimates increase when we lift the confidence level. One day $\mathrm{VaR}$ is calculated for a single worst day loss, but ten-day $\mathrm{VaR}$ is calculated for the worst ten days. From the table, we can say that we are 90\%, 95\% and 99\% confident that AB bank's total loss would not exceed 18413, 24740 and 41292 BDT in a single day respectively. The second part of the table is slightly different. In a similar manner, we are $90 \%, 95 \%$ and $99 \%$ confident that $\mathrm{AB}$ bank's total loss would not exceed 58228,78236 and 130578 BDT. But the difference is that these values are not calculated for a single day. The computed maximum loss will not exceed the worst ten days for AB bank.

Table 5: Value-at-risk of Bank Asia Limited at different time intervals from 2012-2020

\begin{tabular}{|c|c|c|}
\hline \multicolumn{3}{|c|}{ Value-at-risk of Bank Asia Limited } \\
\hline Time Periods & Confidence Level (\%) & Amounts in BDT \\
\hline \multirow{3}{*}{ 1-Day } & $90 \%$ & $-7,902$ \\
\cline { 2 - 3 } & $95 \%$ & $-10,492$ \\
\cline { 2 - 3 } & $99 \%$ & $-18,388$ \\
\hline \multirow{3}{*}{ 10-Day } & $90 \%$ & $-24,987$ \\
\cline { 2 - 3 } & $95 \%$ & $-33,178$ \\
\cline { 2 - 3 } & $99 \%$ & $-58,149$ \\
\hline
\end{tabular}

Sources of Data: Author's Calculation

Table 5 discusses VaR estimates of Bank Asia. Bank Asia's VaR estimates are relatively moderate. With $90 \%, 95 \%$ and $99 \%$ confidence, it can be said that the maximum loss for Bank Asia will not exceed 7902, 10492 and 18388 BDT in a single day respectively. On the other hand, it can be assumed that total loss will not be more than 24987,33178 and 58149 BDT for a ten-day period with $90 \%, 95 \%$ and $99 \%$ certainty.

Table 6: Value-at-risk of BRAC Bank Limited at different time intervals from 2012-2020

\begin{tabular}{|c|c|c|}
\hline \multicolumn{3}{|c|}{ Value-at-risk of BRAC Bank Limited } \\
\hline Time Periods & Confidence Level (\%) & Amounts in BDT \\
\hline \multirow{3}{*}{ 1-Day } & $90 \%$ & $-4,933$ \\
\cline { 2 - 3 } & $95 \%$ & $-6,904$ \\
\cline { 2 - 3 } & $99 \%$ & $-12,938$ \\
\hline \multirow{3}{*}{ 10-Day } & $90 \%$ & $-15,598$ \\
\cline { 2 - 3 } & $95 \%$ & $-21,832$ \\
\cline { 2 - 3 } & $99 \%$ & $-40,914$ \\
\hline
\end{tabular}

Sources of Data: Author's Calculation

Table 6 demonstrates that BRAC bank is the second bank in the list with minimal $\mathrm{VaR}$ estimates. It can be inferred from the excellent daily returns of the bank. For a 
single day, BRAC bank's maximum loss will not be more than 4933, 6904 and 12938 BDT and we are 90\%, 95\% and 99\% confident about that. In case of loss happening for a straight ten days, we can predict that its maximum loss for that period will be at best 15598, 21832 and 40914 BDT.

Table 7: Value-at-risk of City Bank Limited at different time intervals from 2012-2020

\begin{tabular}{|c|c|c|}
\hline \multicolumn{3}{|c|}{ Value-at-risk of City Bank Limited } \\
\hline Time Periods & Confidence Level (\%) & Amounts in BDT \\
\hline \multirow{3}{*}{ 1-Day } & $90 \%$ & $-18,493$ \\
\cline { 2 - 3 } & $95 \%$ & $-24,713$ \\
\cline { 2 - 3 } & $99 \%$ & $-41,397$ \\
\hline \multirow{3}{*}{ 10-Day } & $90 \%$ & $-58,481$ \\
\cline { 2 - 3 } & $95 \%$ & $-78,150$ \\
\cline { 2 - 3 } & $99 \%$ & $-1,30,910$ \\
\hline
\end{tabular}

Sources of Data: Author's Calculation

Table 7 shows the maximum loss for City bank. VaR estimates can also be interpreted by significance level. There is a $10 \%, 5 \%$ and $1 \%$ chance that City bank's total loss will be 18493. 24713 and 41397 BDT or more than that in a single day. For ten days, the minimum loss will be 57481, 78150 and 130910 BDT or more than that and we are $10 \%, 5 \%$ and $1 \%$ sure of that respectively.

Table 8: Value-at-risk of Dhaka Bank Limited at different time intervals from 2012-2020

\begin{tabular}{|c|c|c|}
\hline \multicolumn{3}{|c|}{ Value-at-risk of Dhaka Bank Limited } \\
\hline Time Periods & Confidence Level (\%) & Amounts in BDT \\
\hline \multirow{3}{*}{ 1-Day } & $90 \%$ & $-8,065$ \\
\cline { 2 - 3 } & $95 \%$ & $-10,831$ \\
\cline { 2 - 3 } & $99 \%$ & $-19,040$ \\
\hline \multirow{3}{*}{ 10-Day } & $90 \%$ & $-25,503$ \\
\cline { 2 - 3 } & $95 \%$ & $-34,250$ \\
\cline { 2 - 3 } & $99 \%$ & $-60,211$ \\
\hline
\end{tabular}

Sources of Data: Author's Calculation

Table 8 shows that the maximum loss for 1 -day-VaR of Dhaka bank is 8065,10831 and 19040 BDT with respective confidence levels. If a loss occurs over a period of ten days, it will not exceed 25503, 34250 and 60211 BDT. 
Table 9: Value-at-risk of Eastern Bank Limited at different time intervals from 2012-2020

\begin{tabular}{|c|c|c|}
\hline \multicolumn{3}{|c|}{ Value-at-risk of Eastern Bank Limited } \\
\hline Time Periods & Confidence Level (\%) & Amounts in BDT \\
\hline \multirow{3}{*}{ 1-Day } & $90 \%$ & $-7,462$ \\
\cline { 2 - 3 } & $95 \%$ & $-11,202$ \\
\cline { 2 - 3 } & $99 \%$ & $-18,574$ \\
\hline \multirow{3}{*}{ 10-Day } & $90 \%$ & $-23,598$ \\
\cline { 2 - 3 } & $95 \%$ & $-35,423$ \\
\cline { 2 - 3 } & $99 \%$ & $-58,736$ \\
\hline
\end{tabular}

Sources of Data: Author's Calculation

On the worst day, Eastern bank can incur loss up to 7462, 11202 and 18574 BDT. In the ten bad days, it will incur loss no more than 23598, 35423 and 58736 BDT.

Table 10: Value-at-risk of Jamuna Bank Limited at different time intervals from 2012-2020

\begin{tabular}{|c|c|c|}
\hline \multicolumn{3}{|c|}{ Value-at-risk of Jamuna Bank Limited } \\
\hline Time Periods & Confidence Level & Amounts in BDT \\
\hline \multirow{3}{*}{ 1-Day } & $90 \%$ & $-4,400$ \\
\cline { 2 - 3 } & $95 \%$ & $-6,146$ \\
\cline { 2 - 3 } & $99 \%$ & $-10,235$ \\
\hline \multirow{3}{*}{ 10-Day } & $90 \%$ & -13915 \\
\cline { 2 - 3 } & $95 \%$ & -19435 \\
\cline { 2 - 3 } & $99 \%$ & -32365 \\
\hline
\end{tabular}

Sources of Data: Author's Calculation

The numbers of Jamuna Bank are excellent. The VaR estimates are the least among the ten banks, which indicates a prospective investment opportunity under this bank. Jamuna Bank will be likely to incur a maximum loss of 4400, 6146 and 10235 BDT in a single day. On the other hand, during a ten-day crisis period, the likely chance for maximum loss of Jamuna bank will be 13915, 19435 and 32365. 
Table 11: Value-at-risk of Mutual Trust Bank Limited at different time intervals from 2012-2020

\begin{tabular}{|c|c|c|}
\hline \multicolumn{3}{|c|}{ Value-at-risk of Mutual Trust Bank Limited } \\
\hline Time Periods & Confidence Level (\%) & Amounts in BDT \\
\hline \multirow{3}{*}{ 1-Day } & $90 \%$ & $-7,399$ \\
\cline { 2 - 3 } & $95 \%$ & $-10,799$ \\
\cline { 2 - 3 } & $99 \%$ & $-20,213$ \\
\hline \multirow{3}{*}{ 10-Day } & $90 \%$ & $-23,399$ \\
\cline { 2 - 3 } & $95 \%$ & $-34,151$ \\
\cline { 2 - 3 } & $99 \%$ & $-63,920$ \\
\hline
\end{tabular}

Sources of Data: Author's Calculation

Mutual Trust's likely maximum loss amounts are 7399, 10799 and 20213 BDT in the one-day period. In contrast, if we consider the ten-day period, Mutual Trust bank might incur losses of 23399, 34151and 63920 BDT. Mutual Trust Bank has moderate market risk exposure because its one-day VaR and ten-day VaR are neither extremely high nor extremely low. Thus, it gives investors a trade-off between the two extreme points. Investors can settle for moderate $\mathrm{VaR}$ and moderate profits. They will not lose too much money if they invest in this bank.

Table 12: Value-at-risk of National Bank Limited at different time intervals from 2012-2020

\begin{tabular}{|c|c|c|}
\hline \multicolumn{3}{|c|}{ Value-at-risk of National Bank Limited } \\
\hline Time Periods & Confidence Level (\%) & Amounts in BDT \\
\hline \multirow{3}{*}{ 1-Day } & $90 \%$ & $-14,944$ \\
\cline { 2 - 3 } & $95 \%$ & $-19,947$ \\
\cline { 2 - 3 } & $99 \%$ & $-37,850$ \\
\hline \multirow{3}{*}{ 10-Day } & $90 \%$ & $-47,257$ \\
\cline { 2 - 3 } & $95 \%$ & $-63,077$ \\
\cline { 2 - 3 } & $99 \%$ & $-1,19,692$ \\
\hline
\end{tabular}

Sources of Data: Author's Calculation

There is a $10 \%$ chance that in a single day National Bank's total loss will be at least 14944 BDT or more than that. There is also a $5 \%$ and $1 \%$ chance that the minimum loss of National bank is equivalent to 1994 and 37850 BDT or more than these amounts. When we consider the ten-day period, the minimum cut off point for loss of National bank is 47257, 63077 and 119692 BDT. 
Table 13: Value-at-risk of Uttara Bank Limited at different time intervals from 2012-2020

\begin{tabular}{|c|c|c|}
\hline \multicolumn{3}{|c|}{ Value-at-risk of Uttara Bank Limited } \\
\hline Time Periods & Confidence Level (\%) & Amounts in BDT \\
\hline \multirow{3}{*}{ 1-Day } & $90 \%$ & $-16,434$ \\
\cline { 2 - 3 } & $95 \%$ & $-22,979$ \\
\cline { 2 - 3 } & $99 \%$ & $-41,059$ \\
\hline \multirow{3}{*}{ 10-Day } & $90 \%$ & $-51,968$ \\
\cline { 2 - 3 } & $95 \%$ & $-72,667$ \\
\cline { 2 - 3 } & $99 \%$ & $-1,29,840$ \\
\hline
\end{tabular}

Sources of Data: Author's Calculation

Table 13 talks about the VaR projections of Uttara bank. It will be likely to have losses equivalent to 16434,22979 and 41059 BDT. For ten-day worst possible losses, Uttara bank may incur losses up to 51968, 72667 and 129840 BDT.

\subsection{Value-at-risk of the Total Portfolio at Different Time Intervals}

Portfolio VaR demonstrates the total maximum loss in a given confidence level. Each of the ten banks altogether constructs the portfolio. In this study, the total portfolio was assumed to be 50,00,000 BDT. And the portfolio VaR refers to the aggregate loss of the entire portfolio.

Table 14: Value-at-risk of the total portfolio at different time intervals from 2012-2020

\begin{tabular}{|c|c|c|}
\hline \multicolumn{3}{|c|}{ Value-at-risk of Total Portfolio } \\
\hline Time Periods & Confidence Level (\%) & Amounts in BDT \\
\hline \multirow{3}{*}{ 1-Day } & $90 \%$ & $-81,651$ \\
\cline { 2 - 3 } & $95 \%$ & $-1,10,733$ \\
\cline { 2 - 3 } & $99 \%$ & $-1,96,234$ \\
\hline \multirow{3}{*}{ 10-Day } & $90 \%$ & $-2,58,202$ \\
\cline { 2 - 3 } & $95 \%$ & $-3,50,170$ \\
\cline { 2 - 3 } & $99 \%$ & $-6,20,546$ \\
\hline
\end{tabular}

Sources of Data: Author's Calculation

Table 14 depicts portfolio VaR estimates. If we have 50,00,000 BDT worth of portfolio invested in ten local commercial banks, we may incur a loss of 81,651 BDT in a single day, and we are $90 \%$ confident about this prediction. With a $95 \%$ and 99\% confidence level, we might face losses up to 11733 BDT and 196234 BDT respectively in our portfolio. In contrast, if we consider a ten-day loss period, our portfolio will face a different set of losses. For instance, the maximum loss for the ten-day scenario can be 258202 BDT with a $90 \%$ confidence level or 350170 BDT with a $95 \%$ confidence level or 620546 BDT with a $99 \%$ confidence level. 


\subsection{Generation-Wise Var Range of The Banks}

The study contains ten banks from various generation groups. Four banks were selected from the first-generation banks and four were selected from the secondgeneration banks. Only two banks were selected from the third generation. In the following table, the range of the VaR estimates is discussed for these banks.

Table 15: Value-at-risk according to the generations of the banks

\begin{tabular}{|c|c|c|}
\hline Banks as per generation & 1-DAY VaR (Low to High) & 10-DAY VaR (Low to high) \\
\hline 3rd & $4,000-12,000$ & $13,000-40,0000$ \\
BRAC Bank Ltd. & & \\
Jamuna Bank Ltd. & & \\
\hline $\mathbf{2}^{\text {nd }}$ & $7,000-20,000$ & $23,000-63,000$ \\
Bank Asia Ltd. & & \\
Dhaka Bank Ltd. & & \\
Eastern Bank Ltd. & & $47,000-1,30,000$ \\
Mutual Trust Bank Ltd. & & \\
\hline 1st & $14,000-41,000$ & \\
AB Bank Ltd. & & \\
City Bank Ltd. & & \\
Uttara Bank Ltd. & & \\
National Bank Ltd. & &
\end{tabular}

Sources of Data: Author's Calculation

Table 15 shows the range of VaR estimations according to the banks' establishment year. It is clearly visible that the least amount of VaR is recorded by the thirdgeneration banks. Jamuna and BRAC bank limited has the lowest market risk exposure that ranges from BDT 4,000 to 12,000 for a single day and BDT 13,000 to 40,000 for a ten-day period. And the maximum market risk exposure is recorded by the banks from first-generation. They can lose from BDT 14,000 to 41,000 in the worst day and BDT 47,000 to 1,30,000 in ten-day period. Second generation banks have moderate market risk exposure with BDT 7,000-20,000 in a single day and BDT 23,000 to 63,000 in ten days.

\subsection{Major Findings}

The major findings of this study are described in the following:

Four banks out of the ten have a positive pattern in their stock value for the selected timeline which started in 2012 and ended in 2020. BRAC, Mutual Trust, Jamuna and Bank Asia were able to increase their share value by $217 \%, 90 \%, 22 \%$ and $6 \%$ respectively.

Five banks showed a declining trend in their share price. Shares of $A B$ and National bank have declined more than $60 \%$ whereas Uttara and Dhaka bank's share price were dropped below $50 \%$. City bank holds a slightly better position with a $15 \%$ reduction in its stock value. In the case of the Eastern bank, it can be said that its 
share value remained almost unchanged with a $0.4 \%$ drop.

BRAC bank had a $116 \%$ average percentage return and Bank Asia had a 22,477 average BDT return.

Jamuna and BRAC bank limited has the lowest exposure to market risk because their 1-day and 10-day VaR had the lowest values among the other eight banks. Both of the banks have shown that if anyone invested in any of them, the investor is likely to incur a loss (in a single day) around BDT 5,000 to 13,000 for various confidence intervals and a loss around (in ten days) BDT 16,000 to 41,000 (for BRAC Bank) and BDT 14,000 to 33,000 (for Jamuna Bank).

Four banks, including Eastern, Mutual Trust, Dhaka and Bank Asia, have neither high nor low market risk exposures. The VaR estimates of these banks are within BDT 7,000 to 20000 for the worst day and BDT 23,000 to 63,0000 for ten days.

$\mathrm{AB}$, Uttara, City and National bank recorded the highest VaR calculation in the study and suggested that they are highly subject to market risk. Their single day VaR estimate ranges from BDT 14,000 to 41,000- and ten-day estimate are around BDT 4,70,000 to $1,30,000$.

Portfolio VaR estimation is recorded BDT 81,651 (at 90\%), 1,10,733 (at 95\%) and $1,96,234$ (at 99\%) if maximum losses are considered for a single day. The portfolio will lose substantial amount such as BDT 2,58,202 (at 90\%), 3,50,170 (at 95\%) and $6,20,546$ (at $99 \%$ ) for ten-days.

\section{Conclusion}

The goal of this study is to determine the market risk of ten local commercial banks using VaR implementing historical simulation method. Initially, 1-day and 10-day $\mathrm{VaR}$ are calculated for the ten banks. Later, a portfolio VaR is calculated to indicate portfolio returns from historical data. Among the ten banks, some showed an upward trend and some had a downward trend in their share values. The study was for the period between 2012 to 2020. In these nine years, BRAC, Mutual Trust, Jamuna and Bank Asia were able to increase their share value by $217 \%, 90 \%, 22 \%$ and $6 \%$ respectively. Shares of $\mathrm{AB}$ and National, Uttara. City and Dhaka bank showed a downward trend in their share prices. Eastern bank remained in a neutral position. BRAC bank had the best average percentage return of $116 \%$ and Bank Asia had the highest average BDT return of 22,477. Investing in these banks will surely generate adequate profits for an investor. Jamuna and BRAC Bank are the two best choices if anyone wants to minimize his loss of investment. For mediocre market risk, investors can look up to the four banks, including Eastern, Mutual Trust, Dhaka and Bank Asia. The worst market risk exposure is recorded for AB, Uttara, City and National bank. Among the ten banks, a rational investor does not want to invest in them if historical returns emerge in the future. The results of this study might help a reader if he is looking to identify the risks faced by these banks and tries to have an idea about the nature of the market risk scenario for these banks. Further work can be done by overcoming the limitations that were present in this study. 
Studies like this should be done more to give a boost to the banking sector of Bangladesh.

\section{ACKNOWLEDGEMENTS:}

I would like to express my heartiest gratitude to my supervisor Dr. Raad Mozib Lalon (Associate Professor, Department of Banking and Insurance, University of Dhaka). He was always there to guide and cheer me with his valuable time, experience, expertise and perspectives.

I am also thankful to myself for all the efforts undertaken to finish this paper. I hereby declare that this paper is prepared by myself and myself only and I will be held liable if found otherwise.

\section{References}

[1] Alam, M. Z., and Musukujjaman, M. (2011). Risk management practices: A critical diagnosis of some selected commercial banks in Bangladesh. Journal of Business and Technology (Dhaka), 6(1), 15-35.

[2] Alexander, C. (2008). Market risk analysis, practical financial econometrics (Vol. 2). John Wiley \& Sons.

[3] Allen, D. E., and Powell, R. (2009). Transitional credit modelling and its relationship to market value at risk: an Australian sectoral perspective. Accounting \& Finance, 49(3), 425-444.

[4] Berkowitz, J., Christoffersen, P., and Pelletier, D. (2011). Evaluating value-atrisk models with desk-level data. Management Science, 57(12), 2213-2227.

[5] Grum, A. (2007). Measuring Market Risk for Commercial Banks in the Volatile Environment of an Emerging Market Economy. South East European Journal of Economics and Business, 2(2), 89-94.

[6] Jorion, P. (2007). Financial risk manager handbook (Vol. 406). John Wiley \& Sons.

[7] Smit, W. (2009). Determining the fair level of economic capital for credit and market risk in commercial banks (Doctoral dissertation, North-West University).

[8] Uylangco, K., and Li, S. (2016). An evaluation of the effectiveness of Valueat-Risk (VaR) models for Australian banks under Basel III. Australian Journal of Management, 41(4), 699-718.

[9] Winker, P. and Maringer, D., 2007. The convergence of optimization-based estimators: Theory and application to a GARCH model. forthcoming.

[10] Yap, V. C., Ong, H. B., Chan, K. T., and Ang, Y. S. (2010). Factors affecting banks' risk exposure: Evidence from Malaysia. European Journal of Economics, Finance and Administrative Science, (19). 